\title{
Review of: "FDA defined tobacco product"
}

\author{
Clive Bates
}

Potential competing interests: The author(s) declared that no potential competing interests exist.

This definition misses the main point. The definition of an FDA defined-tobacco product is a legal definition. It should be defined only by reference to the law that forms the definition. This may change over time through changes in legislation and case law. The definition of an "FDA-defined tobacco product" must, ontologically, be identical to the definition used by FDA.

This is a follows:

An FDA defined tobacco product is any product that meets the definition of a tobacco products set out in the United States Food, Drug and Cosmetic Act and as interpreted by the courts. Tobacco product is defined at Section 201 of the Federal Food, Drug, and Cosmetic Act (21 U.S.C. 321) in subsection (rr).

1. The term 'tobacco product' means any product made or derived from tobacco that is intended for human consumption, including any component, part, or accessory of a tobacco product (except for raw materials other than tobacco used in manufacturing a component, part, or accessory of a tobacco product).

2. The term 'tobacco product' does not mean an article that is a drug under subsection $(\mathrm{g})(1)$, a device under subsection (h), or a combination product described in section 503(g).

See: 21 USC $321(r r)$

Relevant case law includes but is not limited to:

FDA v. Brown \& Williamson.Supreme Court (98-1152) 529 U.S. 120 (2000)

Sottera v. FDA United States Court of Appeals, District of Columbia Circuit. No. 10-5032. (2010)

Note that all countries have legal definitions of tobacco products for trade, administrative and excise duty purposes. There is no reason to follow these definitions in science and it is a peculiarity of the United States that researchers use legal definitions that may be unhelpful scientifically. 